\title{
On the psychological component in the preparation of a future musician teacher
}

\author{
Natalya Garipova $^{{ }^{*}}$ \\ ${ }^{1}$ V.I. Vernadsky Crimean Federal University, Republic of Crimea, Simferopol, Prospekt Vernadskogo \\ 4, Russia.
}

\begin{abstract}
Annotation. The article reveals the pragmatic aspect of the psychological training of future music teachers and reveals its specificity. This specificity lies in the fact that knowledge and skills from the field of psychology in the professional activity of a music teacher should ensure the comprehension of the emotional-figurative content of a musical work, and not familiarization with it as an object of study, as it happens in the development of other educational disciplines. The role of psychological knowledge for solving many other tasks solved in the process of musical education, carried out both in collective and individual forms, is also indicated. At the same time, two ways of forming psychological competencies are indicated - explicit, associated with the module of psychological disciplines, and implicit, which consists in the fact that psychological knowledge penetrates into the depths of performing and musical-theoretical training, providing an understanding of the mechanisms of perception, performance of music and mastering the algorithms of the teacher's work on creation of conditions for its adequate artistic perception, which is the comprehension of musical meaning. In the study of the problem of the mechanisms of the emotional impact of music and the emergence of non-auditory sensations and perceptions are considered; the importance of mastering this (essentially psychological) information for the future musician teacher is shown. The proposed way of improvement the psychological training of a teacher-musician provides a solution to a dual task - improvement his personal qualities (which is facilitated by the perception of high music) and improvement his professional skill in organizing the process of musical perception of learners. This is able to ensure the birth of deep feelings in them.
\end{abstract}

\section{Introduction}

Knowledge and skills from the field of psychology are an important component of the competence of a teacher in any academic discipline. Effective organization of the educational process (transfer of scientific information, formation and development of skills and abilities of learners) is impossible without this knowledge and skills. The psychological knowledge of the teacher is no less relevant in the work of a formation of the child's

*Corresponding author: natamigo@,rambler.ru 
personal qualities, of a management of the team. The role of this knowledge is also important for self-improvement processes based on reflection and "peering" into the depths of one's inner world. This aspect in the formation of the teacher's personality is also very important and recognized by scientists. It would be absurdly to admit that the educational process is completely independent of the personal qualities of the mentor. All these aspects of the psychological component in the teacher's activity serve to explain why it is the foundation for any direction of teacher education. However, each direction, and even more so the educational focus, presupposes its own scope of competencies from the field of psychology, as well as its own methods of acquiring these competencies. A special status in this regard is characteristic of disciplines related to art, and in particular, to music.

The fact is that music, like art in general, stores and transmits information valuable to a person, which is a system of personal meanings [1]. If science its attention focuses on knowledge that reflects the objective laws of the world, then art focuses on the relationship of a person to world, to another man, to himself. This difference in cognitive attitudes is partly responsible for the fact that scientists distinguish between meaning and sense. The issue of distinguishing between these two phenomena has been discussed more than once in the scientific literature $[2,3,4]$.

A number of researchers (E. Artemieva, D. Leontiev), distinguishing sense and meaning (primarily personal), associate the latter with human experiences, which are represented not only by emotions, but also by the activity of the sensory-perceptual sphere of the psyche [3, 5]. With this understanding of the meaning, the role of the body is especially emphasized. This is found in the works of N. Kolyadenko, V. Medushevsky, V. Nalimov [6, 7, 24, 8]. For instance, V. V. Medushevsky writes: "... The infinitely rich information encoded in the sound parameters of intonation is read not by the mind, but by the dynamic states of the body" [7]. E. Gendlin, M. Johnson, G. Lakoff also point to the activity of many mental systems and at the same time to shifts in the body during meaning processes $[9,10,11]$. It is in this way that the experienced attitude (state) of a person (subject) to an object of meaning is manifested. This state underlies the meaning processes. Many researchers call this state an intentional state (intentionality).

If sense is focused on an object (on a subject of meaning, on reference), then meaning is conditioned by the intentional state. Initially, in its genesis, meaning is born from the experience (intentional state) of a person (subject). Being designated (having turned into sign with sense), the meaning can lose the element of the "picture of meaning", which connect with intentional state. It is observed in a science (since the mission of science is to obtain knowledge about the object of study which excluding the subjective element). Science is interested a referensce of signs [12]. Philosophers have long noted that «there is an important distinction to be made between reference and meaning» [13]. Neuropsychological studies by W. Garner, K. Pribram, D. McGuinness confirm this state of affairs. [13, 14, 15, 16]. These studies demonstrating that the human brain processes information in different ways. Information processed by the brain can only be associated with the object of meaning (with reference). But it can also include some kind of redundancy ("redundancy in the sense"). Scientists associate this redundancy with meaning. It must be assumed that the subjective element, conditioned by a person's attitude to the object of meaning, manifests itself in this redundancy.

Recognizing the special role of the subjective component in meaning processes, which manifests itself as the attitude of a person to the subject of meaning (as the attitude that is felt in the body), we gain an understanding of the difference between artificial intelligence and human cognition of the world. The exclusion of the attitude that is felt in the body from the integral picture of the meaning phenomenon does not allow drawing a line of demarcation between human thinking and artificial intelligence, which is constantly improving in its analytic-synthesizing operations. The problem is that often in the 
conditions of education, music is mastered as sense (as a kind of knowledge), despite the fact that music is a meaning objectified in sound.

So, meaning is special information associated not only with the object of meaning, but also with the subject, who feels his own special attitude to this object. And it is music, like no other art form, that is able to easily convey this attitude. At the same time, she manages to convey information about the object of meaning, which can be this or that object, phenomenon, event, finally the world as a whole or the musical creation itself.

It should also be noted that this art, which is a system of vibrations built in a special laws, is able to reflect of the deep nature of the world, which exists as a grandiose system of vibrations inherent in both the cosmos and each thing. It is no accident that $\mathrm{A}$. Schopenhauer put music above all other arts, considering it a "manifestation of the world principle", the objectification of the Hegelian "thing-in-itself", "the quintessence of life and its processes" [17]. The peculiarities of the transmission of such information are that it cannot be comprehended only with the participation of thinking and presupposes the activity of all human mental systems. Therefore, an adequate perception of a piece of music often requires the help of a mentor - a musician teacher.

Taking into account the above, one should recognize the versatility of the psychological component of the process of training a teacher-musician, who must understand the mechanisms of comprehending musical meaning and the peculiarities of organizing musical work (both collective and individual).

To date, there is a large body of literature devoted to the psychological training of a music teacher or indirectly related to this training. Such are the works of D. Kirnarskaya, K. Tarasova, N. Kiyashchenko, G. Tsypin, V. Petrushin, M. Starcheus, A. Toropova [18, 19, $20,21]$. In all these publications, a variety of issues of psychology are presented in the context of the tasks of teacher education in the field of music or in the context of the tasks of music training.

At the same time, one can point to studies in which, from the point of view of psychology, the specificity of musical perception and music itself as an art capable of transmitting high spiritual energies, serving as a means of communication between people and an instrument for comprehending the system of people's meanings. These are the works of V. Medushevsky, E. Nazaikinsky, G. Orlov [7, 22, 23, 24].

Even in the second half of the twentieth century, E. Nazaikinsky defended the particular importance of the psychological aspect in teaching a musician, who believed that psychology should "enter into the very theory of music" $[25,26]$. However, within the framework of music-pedagogical education, the problem of the penetration of psychology into the theory of music remains unresolved to date.

\section{The purpose of the article}

The purpose of the article is to reveal the deep foundations of the psychological training of a musician teacher, highlighting it as a problem of modern music and pedagogical education, and to outline ways to solve this problem. Achievement of this goal implied coverage of issues related not only to the essence of art in a broad philosophical context, but also to the specifics of music and pedagogical education exactly within the limits that allow us to see the need for psychological training of future specialists. The study of the problem is based on understanding the high civilizational mission of music as a translator of the meanings of humanity. The proposed perspective of considering the psychological training of a music teacher also required addressing such issues as meaning, meaning and sense, as well as identifying the degree of elaboration of the problem under study.

The article will show that the specificity of the psychological component of music and pedagogical education is based on solving a dual task - to induce an intentional state in a 
student when communicating with music and at the same time to uncover the mechanisms of this state occurrence.

\section{Statement of the main research material}

As mentioned above, the presence of a psychological component in the system of music and pedagogical education is due to the same reasons that take place in the training of teachers of any other academic discipline. It is clear that without psychological knowledge, it is impossible to effectively solve didactic problems. Knowledge of the regularities of the activity of thinking, the sensory-perceptual sphere of a person is fundamentally necessary for a modern teacher. The effective organization of collective forms of work (which prevail in the modern general education school), as well as the use of an individual approach to each student, also require certain knowledge from the field of psychology.

All this suggests that the block of psychological tuition should take a significant place in the preparation of a future teacher. However, this raises the problem of reconciling a fairly solid amount of knowledge and a very limited number of hours allocated to the discipline in the curriculum. In addition, the discipline of psychology is often connected with pedagogy: both disciplines are combined in one module (this is the case in some institutions of higher education in the field of music education). The effectiveness of the psychological training of a future musician teacher in this regard entirely depends on a successfully found balance between time costs and a system of psychological knowledge, skills and abilities that are clearly built by the teacher-psychologist, required by the future specialist for the successful fulfillment of his professional activities. This way of improving psychological education at music-pedagogical departments can be called explicit - lying on the surface of the educational process and involving the implementation of the discipline by a teacher-psychologist who has an idea of the specifics of organizing music classes.

No less important, and in a number of positions even more significant, is the implicit path of acquiring psychological competence within the framework of music-pedagogical education. This path suggests the convergence of the art of music and psychology. The essence of this convergence lies in the interpenetration and complementarity of two modes of cognition - scientific and artistic. If the scientific method of cognition is entirely based on the activity of thinking, then the artistic (in its musical refraction), as shown above, presupposes the activity of many systems of the human psyche (the activity of sensoryperceptual, emotional, regulatory spheres of the psyche). Only in this way can the meaning of music be comprehended, and only such activity of the psyche testifies to the fact of artistic cognition. The meaning embodied in a musical creation cannot only be understood as sense (as scientific knowledge about an object, completely free from the experienced relationship to this object).

It is clear that such activity of the psyche, going beyond the sphere of thinking, can and, as a rule, takes place primarily in the classes of performing disciplines. Note that it is in these classes that work with the body (with vocal-motor, motor sensations) takes place for the sake of penetrating into the artistic world of musical opus. Each teacher of a musical instrument, vocal, conducting, choir, working with a student on a piece of music, achieves not only awareness, but also a deep experience of music. And this experience exists in the body. This is important both in terms of performing training and in the professional and pedagogical aspect.

There is no doubt that a teacher who is unable to experience music, to feel it with his body, will not be able to instill a love for this art in his students. In the best case, music for him will appear only as a harmoniously built sound, worthy of calculation, but not carrying a deep meaning - information related to life, with the inner world of a person. Therefore, the traditionally used methods of work in the classes of performing disciplines, aimed at 
awakening the emotional, sensory-perceptual spheres of the psyche, are fundamentally important in any direction of musical training in any educational institution, be it a conservatory, an institute of arts or a music-pedagogical faculty.

However, in the conditions of training a future musician-teacher, the work on activating the emotional and sensory-perceptual spheres of the student must acquire a new meaning: the technology of such work must be comprehended by him. This is explained by the fact that in his future musical-pedagogical activity the studing must be able to competently and correctly organize such work with his learners. And this, in the conditions of a pedagogical university, makes special demands on teachers of performing disciplines. A university teacher must find parity between the sphere of the unconscious (and it is always present in the perception of art) and the sphere of the conscious, which is associated with the technology of musical education itself and is always able to level the specific of artistic perception, replacing the comprehension of musical meaning by understanding music as sense (as information of an intellectual plan). This task is poorly solved in the modern pedagogical process. In the future it leads the graduate to blindly copy the methods of working on a piece of music. He does not deeply understand all the details and techniques of working on a piece of music in aspect of embodiment and translating musical meaning.

Such work involves an explanation of the mechanisms of the emergence of emotions in the perception, performance of music. The problem of the emotional impact of music has long been of interest to psychologists and musicians. In this regard, we can mention the studies of L. Meyer, M. Budd, P. Kivy, J. Sloboda, C. Clkrumhansl, P. Juslin, L. Västfjäl, R. Hatten, J. Robinson, K. Scherer, E. Coutinho [27, 28, 29, 30, 31, 32, 33, 34, 35, 36]. Among the Russian-speaking authors can be called V. Petrushin, V. Holopova $[19,37]$.

If we look at the problem of the emergence of emotions in the perception of music from the point of view of the psychological mechanisms of this process, then we can distinguish three paths (or mechanisms). Each such path includes several mechanisms [38]. The first path of emotional impact of music can be called psychophysiological. The emotional response within this pathway is determined by the regularities of the functioning of the auditory analyzer, the brain. For example, it is well known that a very loud sound, lasting a fairly long period of time, can cause negative emotion. This is due to the fact that such sounding puts excessive pressure on the auditory analyzer, causing excessive stress and, as a result, a negative emotional reaction. However, a very quiet sound that lasts for a long time can also cause such an emotional reaction. Sounding like this forces the listener to strain their hearing analyzer and body along with it to hear the sound. And if this continues for a long time, the person will have a negative emotion. Something similar takes place with the perception of some timbres.

It is clear that explaining to the student such patterns (patterns of generating emotions when perceiving music) in the classes of performing disciplines is necessary for a number of reasons. Firstly, they should be taken into account, for example, when thinking about a plan for the dynamic development of a piece of music that is being prepared for concert performance. Secondly, this knowledge is necessary for a future musician teacher to organize competent and correct work with his students. Therefore, in the conditions of a pedagogical university, it is advisable to explain to students these mechanisms of emotional response to music.

Another way of emotional impact of music can be called symptomatic. As you know, emotion does not exist outside of its symptoms. Any emotion is felt in the body, in its special states. We feel joy, sadness, sadness, fear, irritation and all other emotions because certain states and processes arise in the internal organs of a person, in his muscles. And we feel these processes and states. Such are, for example, a rapid heartbeat or muscle tightening during torpor. For a person as a social being, the expressive symptoms of emotional reactions are fundamentally important. These are the symptoms that we are able 
to observe in each other. These include facial expressions, pantomime, speech intonations and the associated breathing pattern. Thanks to these symptoms, in our everyday life, we understand the emotions of other people and experience with them, sympathize with them their joy or sadness. Music simulates many of the symptoms of emotion with ease. When a person listens to a piece of music, he appropriates these symptoms, introduces them into his body and in this way becomes infected with emotion. Therefore, when working on a piece of music, it is fundamentally important to find sound structures that represent models of certain gestures, speech intonations. It is equally important to think over the "picture of breathing" inherent in a musical opus, its phases and depth. Often it is this aspect of the performance of music that makes it possible to distinguish an experienced performer, a master performer, from a "beginning musician".

It is advisable to give the knowledge concerning the considered path (mechanism) of the emotional impact of music in the classes of performing disciplines "in small portions", but constantly. However, they should not constitute a certain block of theoretical information. Their presence in the lesson is appropriate only if the musical material itself is conducive to this, when the modeling of one or another symptom of emotion is actually found in the sound matter. Finding a tempo and rhythm that matches the emotion simulated by a piece of music can be very helpful. As you know, this method (the method of finding the tempo and rhythm that are adequate to piece of art) underlies the famous system of Stanislavsky [39]. At the same time, it is important to remind the student about similar life emotions and feelings, about those situations in which these emotions arose. It will also be appropriate here to turn to works of other types of art - painting, sculpture.

The third way of emotional impact of music can be called subject-situational. Its essence lies in the fact that various objects, phenomena, processes, situations, events of reality can be reflected in a piece of music. The world itself as a whole or the Logos of the universe can also be reflected in a musical opus. Much of that which had a special meaning (significance) for the composer and therefore was reflected in his opus may be of value to the listener as well. If the listener has managed to understand the object reflected in the piece of music, and if this object has a special meaning (value) for him, then he has an emotional response. A similar response can also arise when music resembles one or another significant (important) situation in life for an individual, since this music was at one time being an element of this situation. It seems that in the classes of performing disciplines, future music teachers should receive information about this way of the emergence of emotion when perceiving a piece of music.

In addition to these points, a number of problems should also be named, the psychological side of which can be discussed by a student with a teacher of a particular performing discipline. These include, for example, states of stage excitement, movement clamps, artistry, and artistic transformation in the process of performing a piece of music. All these problems not only arise for the musician from time to time, but also require a conscious solution and mastering the algorithms of this solution on the part of the student.

Psychological knowledge can organically penetrate into the sphere of musicaltheoretical training, - into a sphere that would seem to be very far from both psychology and the live perception of music, which generates experiences. Knowledge, skills and abilities related to psychology are relevant when mastering musical semantic. The methodological setting, which consists in considering music as a phenomenon that objectifies and conveys meaning, naturally presupposes the recognition of the existence of a musical language, a certain system of signs that allows information to be transmitted from sender to addressee.

Despite the fact that since the time of Rousseau musicians began to actively use the phrase "musical language", the question of the musical language cannot be considered finally resolved. One of the controversial points is the understanding of the sign in music. A 
sign is something material that carries information not only about itself, but also information about something else (information about some other object, phenomenon, or about something else). This information can be of very different content. However, it must be processed by the listener's psyche precisely as some additional information that is redundant in the audio-sensory sense. It is important to note that many aspects of sound matter are capable of performing such functions. Therefore, many sound structures and element of sound matter can act as signs in music. In addition, many of them are, as it were, built into each other, which was pointed out by A. Losev at one time [40]. This greatly complicates the comprehension of a musical text in its syntagmatics and makes it difficult to understand it by analogy with a verbal text.

Psychological knowledge in the analysis of the described state of affairs allows us to conclude that it is necessary to organize work in the conditions of music education in such a way as to facilitate in every possible way the activity of the psyche in structuring cognitive material. This can be achieved if many musical structures are mastered as certain models (peculiar patterns). These patterns represent typical rhythmic "formulas", meters, melodic and harmonic turns that are often found. The greater the number of models, the identification of which is carried out "on automatism," the psyche has, the structuring of the sound material is the easier. And this must be understood not only by the teacher, but also by the student. Awareness of the laws of work of the psyche in the perception of musical material will help the future teacher to select the actual musical structures within the framework of a particular genre and style. Undoubtedly, mastering such structures is one of the moments of improving a person's ear for music.

Mastering musical structures has a very positive effect on the functioning of the abovementioned psychophysiological mechanism of the emotional impact of music. The fact is that the so-called dynamic stereotype is an important "tool" for generating emotions. A dynamic stereotype is a well-coordinated system of connections that occurs in the brain due to repeated exposure to stimuli in the same order. Dynamic stereotypes are developed not only on the basis of certain rhythmic, melodic "formulas", harmonic turns, but also on the basis of modes, textured "formulas", musical compositional forms and patterns of musical development.

All these and many other similar elements of musical matter, if mastered by the listener, facilitate his perception. If they were mastered by the listener, they participate in the creation of a psychological attitude, create the effect of anticipation, which can cause positive emotion both in the case of actualization of the expected, and in the case of "deceiving" expectations. The mechanism of such expectations and "deceptions" has been studied in detail and described in the scientific literature [41]. Despite this, in the practice of musical theoretical training, purposeful work on mastering of such musical structures is usually absent.

Undoubtedly that this state of affairs should be corrected primarily in the conditions of training a teacher-musician. At the same time, students, as future music teachers, should gain knowledge about the psychological aspect of such work on the mastering of musical structures. This is due to the fact that in their professional activities they need to competently and correctly organize work on the development of musical ear and musical thinking in their pupils.

Leaving aside the problems associated with the peculiarities of musical communication, as well as with the peculiarities of the embodiment of meaning in musical-sound matter, we nevertheless note the existence in music of certain sound structures ("semantic formulas", intonations), which are similar to lexemes of the verbal language that refer the listener to a particular reality, concept, to the figurative sphere, etc. In English-language musicology, these sound structures are called topics. They were investigated in the works of K. Agawu, R. Hatten, R. Monelle [42, 43, 44]. Scientists have shown that these structures reflect 
different layers of culture. In Russian-speaking science, L. Shaimukhametova addressed the problem of such intonational formulas [45].

Despite the fact that the existence of topics (intonations) makes music look like verbal speech and allows a person to actively use thinking in its perception, the processes of mastering musical vocabulary should not be analogous to the processes of mastering words of a foreign language. The development of musical vocabulary should be based on the perception of musical works (their fragments) in the fullness of the sensory-perceptual activity of students. It is impossible to tell about the musical meaning, since it can only be experienced. According to G. Orlov, music itself is meaning. In this regard, the scientist writes: "... Music does not mean meaning, but it is meaning itself" [23].

The work on mastering the semantics of individual musical means in specific musical contexts is no less valuable in terms of professional development of a future musician teacher. This work consists in the students' awareness of their co-sensations when perceiving musical material. Every person who loves music knows that this art is a source of not only auditory sensations and perceptions. When perceiving a piece of music, as a rule, a gamut of sensations and representations of various modalities arises. Thanks to this, with his opus, the composer is able to convey to the listener information about many objects, phenomena, processes of the surrounding world, and even about those that we perceive in our everyday life without the participation of hearing, with the help of visual, tactile and other analyzers. The problem is how adequate are all these sensations and representations to the sounding work.

In the professional activity of a music teacher, there is always a problem to organize work with a musical opus in such a way as to evoke adequate sensations and percepts in students. At the same time, the musician teacher must understand the origins of inadequate sensations, which, as a rule, is associated with imbalances in the development of certain components of musical ear. All this cannot be done without mastering the semantics of individual musical means, without clarifying the role of each musical means in the musical context.

So, for example, the visual sensation of something light (when perceiving the sound) can be caused not only by the timbre, but also by the high register, the major scale; and the feeling of heaviness is generated by low sounds with viscous articulation and loud dynamics. It is necessary that the future musician teacher, together with the awareness of his non-auditory sensations, should be aware of the musical means that generate these sensations. A future teacher-musician should master the semantics of musical means by this way. Such acquisition of the semantics of musical means forms in him an setting to comprehend what was heard in all the details.

As practice shows, the modern system of musical education forms the mindset to be awareness of only the pitch and temporal plans for the development of a musical work. This is demonstrated by testing of freshmen of music departments of pedagogical universities, which have been carried out over several years. Usually, only 1-2\% of students cope with the task of reflecting in the musical notation all sides of the musical sound that can be noted in the notes (including dynamics, articulation). The overwhelming majority of students try to reflect, first of all, pitch development, while forgetting even about the existence of a musical rhythm.

All this suggests that the upbringing of a musician teacher requires the development of all aspects of his musical ear, and this should be carried out in the context of penetrating into the artistic sphere of musical works. At the same time, the role of each musical means in the embodiment of this musical content is clarified. A fundamentally important moment of such work is the feeling itself (and it can be associated not only with the emotional sphere of a person, but also with a wide variety of non-auditory sensations and 
perceptions), which arises in response to musical sound and allows one to diagnose the effect of the genesis of meaning (a special intentional state).

The very experience (not only emotional) that arises in response to musical sound and allows one to diagnose the effect of the genesis of meaning (a special intentional state) is a fundamentally important aspect of such work. Psychological competence is acquired here in understanding the mechanisms of those semantic processes that arise in a person when perceiving music. Awareness of their own experiences (sensations, emotions, representations, motor acts, etc.), understanding the mechanisms of their occurrence will allow the teacher in his future pedagogical activity to build work on comprehending the musical meaning with his pupils.

\section{Conclusions}

Thus, the psychological component of music and pedagogical education, along with the competencies inherent in a teacher of any specialty, should include knowledge, skills and abilities related to comprehending the musical meaning both when perceiving music and when working on a piece of music related to its performance. Comprehending meaning as a super task in the organization of any work with music presupposes a very solid amount of psychological knowledge when solving it. This knowledge can be successfully mastered provided the convergence of musical and psychological education. Such convergence can easily be realized within the framework of performing and musical-theoretical disciplines, which allow solving a dual task - to cause an intentional state and explain its mechanism. The educational process, organized in this way, equips future music teachers with working methods that ensure the comprehension of musical meaning, which ultimately cultivates the human in a person. However, this raises the problem of psychological training of teachers of music, music-pedagogical faculties, the solution of which requires special research.

\section{References}

1. A.N. Leontiev, Selected psychological works, 2 (1983)

2. D. Gasparyan, The mystery of natural semantics: the transcendental dimension of meaning and the problem of artificial intelligence, Problems of Philosophy, 4, 81-94 (2017)

3. D.A. Leontiev, Psychology of meaning: nature, structure and dynamics of semantic reality (1999)

4. L.T. Ryskeldieva, On grammar and metaphysics of meaning, Problems of Philosophy, 7, 70-80 (2018)

5. E.Yu. Artemieva, Fundamentals of psychology of subjective semantics (1999)

6. N.P. Kolyadenko, Synesthetic musical and artistic consciousness (based on the art of the 20th century) (2005)

7. V.V. Medushevsky, Intonational form of music (1993)

8. V.V. Nalimov, Spontaneity of consciousness. Probabilistic theory of senses and semantic architectonics of personality (1989)

9. E. Gendlin, Experiencing and the creation of meaning: a philosophical and psychological approach to the subjective (1962)

10. M. Johnson, The Body in the Mind: The Bodily Basis of Meaning, Imagination and Reason (1987)

11. G. Lakoff, Women, fire and dangerous things (1987) 
12. N. M. Garipova, On the meanings of meaning and its hypostases, Sociology, 1, 210-221 (2020)

13. K. Pribram, Music, Mind, and Brain, Brain Mechanism in Music: Prolegomena for a Theory of the Meaning of Meaning, 21-36 (1982)

14. W. Garner, Uncertainty and Structure as Psychological Concepts (1962)

15. K. Pribram, D. Mc Guinness, Arousal, activation and effort in the control of attention, Psych. Rev., Psychological Review, 82 (2), 116-149 (1975)

16. K. Pribram, Origins and Evolution of Language and Speech, Language in a sociobiological frame, 798-809 (1976)

17. A. Schopenhauer, The world as will and representation, 1 (1998)

18. D.K. Kirnarskaya, K.V. Tarasova, N.I. Kiyashchenko, G.M. Tsypin, Psychology of musical activity: Theory and practice (2003)

19. V.I. Petrushin, Musical psychology (2019)

20. M.S. Starcheus, The musician's hearing (2003)

21. A.V. Toropova, Musical psychology and psychology of music education (2019)

22. E.V. Nazaikinsky, The sound world of music (1988)

23. G.A. Orlov, The tree of music (1992)

24. I. Cross, E. Tolbert, Music and meaning, The Oxford Handbook of Music Psychology, 24-34 (2009)

25. E.V. Nazaikinsky, Ways of improving musical theoretical disciplines, Soviet music, 2, 64-78 (1983)

26. E.V. Nazaikinsky, About the Department of Music Theory, Journal of the Society of Music Theory, 1, 12-30 (2013)

27. L.B. Meyer, Emotion and meaning in music (1957)

28. M. Budd, Motion and Emotion in Music: How Music Sounds, British Journal of Aesthetics, 23 (3), 209-221 (1983)

29. P. Kivy, Sound Sentiment. An Essay on the Musical Emotions (1989)

30. J.A. Sloboda, Music structure and emotional response: some empirical findings, Psychology of Music, 19, 110-120 (1991)

31. C.L. Krumhansl, An exploratory study of musical emotions and psychophysiology, Canadian Journal of Experimental Psychology, 51, 336-353 (1997)

32. P.N. Juslin, J. A. Sloboda (eds.), Music and Emotion (2001)

33. C.L. Krumhansl, Music: A link between cognition and emotion, Current Directions in Psychological Science, 11, 45-50 (2002)

34.P.N. Juslin, 1.D. Västfjäl, Emotional responses to music: The need to consider underlying mechanisms, Behavioral and Brain Sciences, 31, 559-575 (2008)

35. R. Hatten, J. Robinson, Emotions in Music, Music Theory Spectrum, 34 (2), 71-106 (2012)

36. K. Scherer, E. Coutinho, How music creates emotion: A multifactorial process approach, The Emotional Power of Music: Multidisciplinary perspectives on musical arousal, expression, and social control, 121-145 (2013)

37. V.N. Holopova, Musical emotions (2010)

38. N.M. Garipova, Psychological origins of the emotiogenicity of music, Questions of psychology, 4, 78-86 (2011) 
39. K.S. Stanislavsky, The work of the actor on himself (1955)

40. A.F. Losev, Music as a subject of logic (1990)

41. D. Huron, Sweet Anticipation: Music and the Psychology of Expectation (2006)

42. K. Agawu, Playing with signs. A semiotic interpretation of classic music (1991)

43. R. Hatten, Interpreting Musical Gestures, Topics, and Tropes: Mozart, Beethoven, Schubert (Musical Meaning and Interpretation) (2004)

44. R. Monelle, The musical topic: hunt, military and pastoral (Musical Meaning and Interpretation) (2006)

45. L.N. Shaimukhametova, Migrating intonation formula and the semantic context of a musical theme: Research (1999) 